\title{
मानव जीवन में संस्कारों का महत्व एवम् प्रयोजन
}

डॉ॰ रवि प्रकाश'

संस्कार हिन्दू-धर्म अथवा किसी भी धर्म या सम्प्रदाय में महत्वपूर्ण अंग हैं। संस्कार प्राचीन भारतीय समाज के आदर्शों तथा महत्वकांक्षाओं को भी प्रकट करते हैं। मनुष्य तथा अदृश्य आध्यात्मिक शक्तियों के माध्यम् के रूप में संस्कारों में कई तत्वों का विकास हुआ था। ये आध्यात्मिक शक्तियाँ अनेक अवसरों पर मनुष्य के जीवन में हस्तक्षेप करती थीं जिसके फलस्वरूप मानव जीवन प्रभावित होता था। इसलिए मानव जीवन को सफल बनाने के लिए मनुष्य संस्कारों का प्रयोग करता है। संस्कारों का विधि-विधान भारतीय संस्कृति के विभिन्न धर्मों में किया जाता है, जिससे मानव बिना किसी विधन के अपना विकास और अभिवृद्धि, देवों तथा दिव्य शक्तियों से सामयिक निर्देश और सहायता प्राप्त कर सकें। संस्कारों के अनेक अंगो के मूल में यही विश्वास है कि जीवन का प्रत्येक समय किसी न किसी देवता पर अधिष्ठित है।

संस्कारों का भौतिक उद्देश्य, पशु, संतान, दीर्घ आयु, सम्पति, समृद्धि और बुद्धि की प्राप्ति करना है। संस्कार गृह कृत्य हैं और स्वभावतः उनके अनुष्ठान के समय घरेलू जीवन के लिए आवश्यक सभी वस्तुओं की भावना देवों से की जाती है। हिन्दुओं का यह विश्वास है कि आराधना और प्रार्थना के माध्यम से उनकी इच्छाओं और आकांक्षाओं को देवता जान लेते हैं तथा पशु, संतान, अन्न, स्वास्थ्य तथा सुन्दर शरीर और तीक्षण बुद्धि के रूप में उनकी पूर्ति करते हैं। मनु स्मृति में कहा गया है कि -

स्वाध्यायेन ब्रतैर्हेमिस्रै विधेनेज्यया सुतैः।

महायज्ञैश्च यज्ञैश्च ब्राह्मीयं क्रियते तनुः।

अर्थात् स्वाध्याय, व्रत, होम, देव और ऋषियों के तर्पण, यज्ञ, सन्तानोत्पति व पंचमहायज्ञों के अनुष्ठान से यह शरीर ब्रह्म प्राप्ति एवम् पवित्रता के योग्य बन जाता है। यह सिद्धान्त प्रचलित था कि उत्पन्न होते समय प्रत्येक व्यक्ति शूद्र होता है अतः पूर्ण विकसित होने के लिए उसका संस्कार व परिमार्जन करना आवश्यक होता है। बह्म संस्कारों से संस्कृत व्यक्ति ऋषियों की स्थिति को प्राप्त कर लेता है तथा देव संस्कारों से संस्कृत व्यक्ति देवों की स्थिति को प्राप्त कर लेता है।

संस्कार जीवन के प्रत्येक भाग को व्याप्त कर लेते हैं। यही नहीं उनके द्वारा मृत्यु के बाद व्यक्ति को आत्म-सिद्धान्त द्वारा भी प्रभावित करने का प्रयास किया जाता है। ये संस्कार इस प्रकार व्यवस्थित किए गये हैं कि जीवन के आरम्भ से ही व्यक्ति उनके प्रभाव में आ जाता है। संस्कार मार्गदर्शक का कार्य करते हैं, जो आयु के बढ़ने के साथ-साथ व्यक्ति के जीवन को एक निर्दिष्ट दिशा की ओर ले जाते हैं।

आध्यात्मिकता हिन्दुत्व की प्रमुख विशेषता है और हिन्दु धर्म का प्रत्येक युग में उससे घनिष्ठ सम्बंध रहा है। हिन्दुओं के इस सामान्य दृष्टिकोण ने संस्कारों को भी आध्यात्म साधन के रूप में परिणित कर दिया। धार्मिक कृत्यों का केन्द्र व्यक्ति नहीं अपितु देवता है। अतः दैहिक संस्कारों सहित सम्पूर्ण यज्ञों का अनुष्ठान देवंता की अराधना के लिए किया जाता था। यहाँ तक कि जब कोई संस्कार उत्सव मनाया जा रहा हो तो उस समय संस्कार पर आधारित देव गीत गाये जाते हैं। इन देव गीतों का गायन गाँव की महिलाओं द्वारा बड़े ही सुरीले ढंग से किया जाता है। इन सांस्कारिक देव गीतों में भगवान राम-कृष्ण आदि का वर्णन होता है। जहाँ पर कोई भी सांस्कारिक उत्सव हो वहाँ पर पूरे गाँव के लोगों, सगे-सम्बन्धियों को आमन्त्रित किया जाता है। गाँव की महिलाएं मिल-जुल कर इन साँस्कारिक देव-गीतों का गायन करती है।

भारत गाँवों का देश है। गाँवों की सँख्या नगरों से अधिक है। लगभग 80 प्रतिशत लोग गाँव में रहते हैं। परन्तु प्रत्येक क्षेत्र के गाँव, नगर पर व नगर, गाँव पर आधारित होते हैं। दोनों का अटूट सम्बन्ध है और उसी परम्परा के कारण ही हमारा लोक जीवन क्रियाशील है।

1 सहायक आचार्य (संगीत), राजकीय महाविद्यालय चौड़ा मैदान, कोटशेरा, शिमला-4 
आधुनिक साहित्य की नवीन प्रवृतियों में लोक का प्रयोग गीत, वार्ता, कथा, नाटक, संगीत और साहित्य आदि से युक्त होकर साधारण जन-मानस, जिसमें पूर्व संचित परम्पराएँ, भावनाएं, विश्वास और आदर्श सुरक्षित हैं तथा जिसमें साहित्यगत सामग्री नहीं अपितु उनके विषयों के अनगढ़ और ठोस रत्न छिपे हैं, यहाँ लोक में परम्परागत प्राचीन तथा साधरण जन समाज का अर्थ व्यक्त है।

लोक का शाब्दिक अर्थ उस जन समूह से है जिसमें धर्म, समाज, संस्कृति और संस्कार विद्यमान होते हैं। लोक वह समीर है जिसमें मनुष्य श्वास लेता है। लोक-गीत जन साधारण द्वारा गाए जाने वाले गीत हैं। इनमें उनकी भावनाएं, रीति-रिवाज, आस्थायें निहित होती हैं। ये लोक गीत उनके कार्य-कलापों से जुड़े होते हैं तथा भाषा में बड़े सरल होने के कारण प्रचलित हैं। लोक साहित्य में भी लोकगीत लोक-मन की सहज आकांक्षाओं की तरल तरंग होने के कारण लोक जीवन में विशिष्ट स्थान बनायें रखने में सक्षम है। लोकगीत अनेक अवसरों, त्योहारों, पर्वो, संस्कारों, मेलों राजनैतिक तथा ऐतिहासिक समारोहों पर गाए जाते हैं। लोक-गीतों को संस्कृति के मुँह बोलते चित्र कहा गया है। लोकगीतों में विभिन्न संस्कारों की वैदिक एवं प्राचीन परम्परा का पूर्ण मिश्रण है। जन्म से मृत्यु पर्यन्त सभी संस्कारों से सम्बन्धित गीतों में अटूट परम्परा के दर्शन होते हैं।

संस्कार उस सागर की तरह हैं जिनकी गहराई में बहुमूल्य गीत रूपी मणियॉ व्याप्त हैं। व्यक्ति की बाल्यावस्था और कौमार्यावस्था यहाँ तक कि गर्भावस्था में ही माता-पिता के भाव, विचार, चिन्तन एवं गीतों का प्रभाव, प्रत्यक्ष-अप्रत्यक्ष रूप से बालक पर पड़ता है। संस्कार गीत, मानव जीवन की यर्थाथ एवं नैसर्गिक अभिव्यक्ति का एक सशक्त साधन हैं। लोक-जीवन की सम्पूर्ण अभिव्यक्ति करना संस्कारों का मुख्य उद्देश्य हैं। संस्कार गीतों में साधारण ग्रामीण जीवन के पहलुओं की सहज एवं सरल व्याख्या मिलती है। इन गीतों के माध्यम से किसी क्षेत्र के रीति-रिवाज एवं परम्पराओं को जाना जा सकता है।

लोक गीतों में संस्कार गीतों का एक विशेष स्थान है। धार्मिक क्षेत्र में बह्मणों का जो कर्मकाण्डी व्यवहार देखने को मिलता है, लोक संस्कृति में वह स्थान स्त्रियों के संस्कार गीतों को प्राप्त है। परन्तु जहाँ पर कर्मकाण्ड अनुष्ठानिक होने के कारण नीरस होता है, वहीं संस्कार गीतों में हर्ष, उल्लास, प्रसन्नता की अनुभूतियों की अभिव्यक्ति रहती है। संस्कार गीतों में गीत, संगीत और काव्य शैली का बोल-बाला विद्यमान रहता है। लोक गीतों में संस्कार गीतों का विशेष महत्व होता है। लोक-गीत बनते, बिगड़ते, उपजे, भूले जाते हैं। परन्तु सांस्कारिक गीतों का अस्तित्व प्राय: स्थाई है। ये भूलते बिसरते नहीं। संस्कारों का क्रमिक प्रवाह संस्कार गीतों को सदैव सुरक्षित रखता है। वस्तुतः इन गीतों में संस्कारों का अनुष्ठानिक रूप विद्यमान रहता है। इनमें जन्म से लेकर मृत्यु तक की मर्यादाएं और मान्यताएं सुरक्षित रहती हैं। विशिष्ट संस्कृति में पुरोहितों के अनुष्ठान का जो स्थान है लोक संस्कृति में वही स्थान सांस्कृतिक लोक-गीतों को प्राप्त है ।

निष्कर्ष रूप में हम कह सकते हैं कि सांस्कारिक गीत तथा लोक जीवन का एक दूसरे के साथ अटूट सम्बन्ध है। सांस्कारिक गीत मानव मन की प्राकृत अभिव्यक्ति है। लोक जीवन की प्रत्येक अनुभूति इन संस्कार गीतों में दृष्टिगोचर होती है। सांस्कारिक गीत, लोक जीवन का ऐसा दर्पण है, जिसमें उनके असली हृदयोदगार प्रकट होते हैं। अतः कहा जा सकता है कि किसी भी क्षेत्र के लोक जीवन को वहाँ के सांस्कारिक गीतों के माध्यम से सरलतापूर्वक समझा जा सकता है। संस्कारों का हमारे व्यावहारिक क्रिया-कलापों में विशेष स्थान है तथा इन्हें अनिवार्य समझा जाता है। उसी प्रकार विभिन्न संस्कारों पर गाये जाने वाले लोक-गीतों का इतना महत्व है कि कोई भी संस्कार इन लोक-गीतों के बिना पूर्ण नहीं माना जाता। 